\title{
REVIEW OF LABOUR MARKET STATISTICS
}

\author{
Dennis Rose and Paul Brown, \\ BERL and Department of Statistics \\ Panel and Discussion
}

This workshop was convened to consider the recommendations of the Review of Labour Market Statistics recently completed by Dennis Rose (BERL). The section begins with a summary of the recommendations. ${ }^{1}$ This is followed by an edited transcript of the workshop itself. 2

\section{Introduction}

\section{Paul Brown, Department of Statistics}

There are three reasons why the Department of Statistics undertook a review of labour market statistics. One, is that the current government reforms, in particular the deregulation of the labour market, called in to question the relevance of many of our statistics, most of which were formulated on the assumption of a regulated market. Two, there have been significant changes in social and economic patterns. For example, the changing nature of work and work conditions and increasing variation in working hours and hours of work, some of which have been occurring over a long period of time. The third factor is a structured reorganisation undertaken in the Department of Statistics which is aimed at bringing together our subject matter statistics. Until recently the Department of Statistics did not have a group of statistics we could call "labour market". We had surveys that produced employment statistics and labour statistics and income statistics. But when someone like Phil Morrison would come to us and say, "I would like some statistics on this topic", we'd have to go hunting all over the place. This wasn't just a problem for labour market statistics, this was a problem for all subject-matter statistics. So we undertook a restructuring and we now have an analytical group called the Labour Market Statistics Unit which is headed by Sharon Evans

Setting up this unit and conducting this review of labour market statistics have gone hand in hand. One of the prime objectives of the review was to assess the adequacy of current labour market statistics. So we're asking the question, "How adequate are these statistics given the changed environment?" And then we are also asking, "What sort of issues are there that the statistics should be addressing, where are the gaps and what changes would be necessary to address those problems?"

Today in the workshop we have two objectives. One is to let you know what is going on, what we' re up to and what our thoughts are. The other is to canvas your views. We would like to hear what you think about the review, whether you think we've missed things and whether you think some of the things we're talking about are not important or whether others haven't received the attention they ought too.

The workshop will take the following form: Dennis Rose, who co-authored the report with Chris Pike, will summarise the review process and the main questions that were addressed. The principle recommendations are given in Table 1 to follow. Comments will then be made by a panel of discussants: Tim Maloney from Auckland University, Michael Fletcher from the Labour Department, and Leslie Haines, from the Ministry of Women's Affairs. We will then open up discussion to the floor.

\section{The Review}

\section{Dennis Rose (BERL) Consultant to Department of Statistics}

Thanks Paul, there are some introductory things I'd like to cover before getting into the main findings of the review. The first is to acknowledge Chris Pike's contribution. He worked alongside me and was invaluable just talking issues through, arguing back and keeping things ticking.

The second thing is the process that we went through. I was working part-time over three months and that meant that there were limits to what we could do. We spent quite a lot of time developing the classification of labour market topics which now appears as an appendix to the report. We used this as a trigger for talking to various government departments and agencies, survey branches within the Department of Statistics, the Employers Federation and the CTU. By the time we had got all that set up I realised we were up against severe time constraints and that we were going to be limited in terms of the number of people we could talk to. ${ }^{2}$

My third introductory point concerns the boundaries of the project. Rodney Lewington emphasised several times when we were first getting underway that I was not to be bound by current surveys and collections. He did not want that defining the field of attention. I haven't done a precise tracking over all the existing surveys but we have touched them all. I was searching for the gaps in our knowledge and so we aimed to stake out the territory in a number of key areas. 
On the formal economy, the starting point was the change in the labour market legislative environment with the passage of the Employment Contracts Act and the loss thereby of what had been a major source of information on wage rates and conditions on an occupational or award basis under the old Industrial Relations Act. I was surprised at the general level of satisfaction with what was currently available. Information on the conditions relating to particular classes of employees, rather than to the industries in which they work, was proposed as something that would be useful. David Archer brought to our attention the English New Eamings Survey which is a sample survey of employees conducted through establishments. Having identified the individuals they are interested in, they send a questionnaire to the employer saying fill this in, remove the identifying slip and send their reports back to us. We then found the Australians were operating a similar survey and looking at the results, I was struck by the wide range of statistics that could be produced. There is industry level data and there is also an occupational focus because the base data relates to individuals. Both the Australians and the UK have also made extensive use of the resulting distributional information.

The content of the questionnaires is fairly elementary although there are more complex questions relating to employment contracts and industrial relations issues. We decided to focus on surveys of this type and talk about their possible use in the New Zealand context. The problem of course is that such surveys are very expensive. The distributional information generated by the surveys is very useful in its own right and would feed in well to a revision of the real disposable income indexes, which the Department of Statistics operates. Survey information would also fit in well if one was trying to build up more comprehensive data on total labour inputs in a national accounting type framework. It would be useful to send such information out to agencies such as Quest Rapuara who are preparing leaflets for school leavers and are looking for economic information to feed in alongside their training module information. Whether such a survey would be worth while, once the cost isknown and the possible range of applications examined more closely, is a key question which needs to be answered by the Department. We've also looked at the possibility of using the database currently used to construct the old Prevailing Weekly Wage Rates Index. This data base could also perform some of the above functions and would offer a lower cost option. The shortcomings are discussed in the report.

The second big area covered in the report is the question of linkages between the household economy and the formal economy. The terms of reference refers to sources of income to the household and factors affecting their supply of labour. These are big areas. Again I thought we should focus on one key area - that relating to the overall accounting of the household sector which in recent years has been discussed mainly in relation to the national accounting framework. The framework which I've developed contains a sequence of four tables. The first would record an individual's formal labour force status, (part-time males and females and so on) cross classified by household and type. The body of the table would include data on average earnings and the numbers of hours a person spends in attachment to the formal economy. The second table would relate to individuals in each household type and show a time allocation covering formal economy time inputs and the types of time use that are recorded in a time use survey such as domestic activities, child care, and recreation. So one would have a matrix which linked individuals by different labour force statuses, spreading their hours across different forms of activity.

There are two further tables. One, relates the status of individuals in the labour force to labour force income and to expenditure. Then the final table, which is the most intrusive in its data requirements, attempts to get a picture of cash flows within the household structure: between people attached to the formal labour force and those who are not. These tables offer a fruitful way of relating peoples individual and household status to both their position in the formal economy and to their time use at home in the community. Such data would enable users to start more meaningful computations of a household account, which could be linked eventually to the main system of national accounts.

The third area covered in the report relates to the dynamics of adjustment in the labour market. Three main areas are discussed. The most expensive proposal relates to the possibility of initiating a longitudinal cohort study or a sample population drawn from the census. I've suggested beginning with fifteen to twenty year olds (or fifteen year olds) and following them forward for fifteen years. This would allow us to trace a group of people who are in transition from dependent status in their originating households, to working life, to forming new households and so on.

Then there is the question of using the household labour force survey to trace transitions between various labour force statuses (see Grimmond in this volume). There are problems in this but the information is of interest and we talk in the report about possible extensions of that capacity. There is also the possibility of introducing retrospective questions. We also recommend pilot testing possible income questions for use in the household labour force survey.

The issue of access to unit record databases is discussed in the report. This is a particularly important issue for researchers. There is a big resource of people in research institutions and the universities who could undoubtedly make profitable use of unit record data held by the Department of Statistics. The problem of course is that such data has been collected under confidentiality conditions and the department quite properly does not want to risk its data collecting ability by breaching that undertaking. That stance is fundamental if the department is to protect its integrity. But note two things, first, in the 
US and Australia, departments do grant access in areas where they have removed personal identifiers. Researchers are accessing unit record data and using it for analytical purposes. We should be looking at offering the same opportunities.

The first steps are being taken. The Department of Statistics is developing the concept of a data laboratory in which a researcher can come in, sit down and design the computer programme which Department of Statistics staff will run. The researcher will get the output but confidentiality of individual records will have been preserved. This is clearly a useful concept. Access to unit records allows researchers to analyse the dynamics of adjustment processes within the labour market. Letting outside researchers access database offers a cost effective way of using data which the Department of Statistics already has. It offers an economic way forward.

The fourth theme of the report is to do with statistics relating to education and training. This I have to say is a nightmare zone, it echoes the nightmare of working and living in a society which is stuck in a no growth situation, in an economy in which we have unemployment rates up to thirty percent among some young people. And the only advice we can offer them on how things might get better is that they should train themselves. If they ask "what for" or "what's the point", we don't have any answer at all. We are in the midst of a radical shift in the organisation of production in a society which is calling for skills and we need to enhance the picture we can draw of the evolving demands of those skills. A number of suggestions have been put forward.

I have touched on the question of getting better economic information into the types of leaflets which are being produced within the Government Service and are available for young people to look at. It's one thing to tell young people how to train to be a motor mechanic but it is also important to be given some idea of what it's actually like in economic terms to be a motor mechanic - what are the wage rates? What's been happening to employment? If we can give some hint as to what we think might be happening then there's a need to make information available to those groups likely to be most affected. One of the more incongruous pages of printed material that I know of, is a page in the United States Year-book headed Occupations. It's the only page on Occupations and its last column tells you how many people they think will be in those occupations in the year 2000. This is part of a regular forecasting process which they've been carrying on for forty years. At a detailed level the forecasts have to be in error but it is interesting to see the amount of effort which the world's largest market economy pays to forecasting labour demand. I also take heart from the kind of material coming out of Paul Callister's presentation this morning which suggests that some broad bits of the picture which we drew a few years ago from the Planning Council look right when you look back on the data. I'll stop at this point and say thank you to the Department of Statistics for the opportunity to work back over an area of great interest to me. These recommendations from the review are summarised in Table 1 a diagram showing the links between the proposed developments is shown as Figure 1.

\section{Panel Responses}

\section{Tim Maloney, University of Auckland}

Let me start by thanking Dennis, Chris Pike and the Department of Statistics for putting together this document. The report highlights some of the critical issues that I think we face in monitoring and analysing the changing labour market in New Zealand. Also I want to applaud the department for setting up the Labour Market Statistics Unit.

I really don't have any major bones to pick with what Dennis and Chris have put together, but I want to emphasise two points, and these are not points that are obviously new to anyone here today. The first is the lack of information or at least reasonable information about wages, earnings and income from the various sources that are currently available through the department. I think a lot has to be done either to include the series of questions in the current survey instruments or to come up with new instruments for gathering this information. Obviously one of the first things to do is to consider very seriously the possibility of including these questions in the Household Labour Force Survey. I think it is probably the most cost effective way of coming up with this information, and I agree that there is probably little need to pilot test these questions as the implications for inclusion in this survey are fairly well understood overseas.

More interesting, is the possibility of gathering wage and earnings information from alternative data sets, and I think the two that are of most interest are the establishment based survey, and while I'm not that familiar with the British and Australian counterparts they would seem to be a very good data source. Even more interesting to me is the longitudinal data base, whether it's a panel of younger or older individuals in the New Zealand economy. I think both sources would be of tremendous interest and value for those academics who are looking at various issues in the New Zealand labour market.

My major comment however has to do with the access of unit record information, the point that Dennis raised earlier. All you need to do is pick up a journal in economics and page through the various articles on the studies of labour markets overseas to find that they are almost entirely based on unit record data. So many of the questions that we talk about in labour economics can only be answered by having some access to unit record data. So many issues and so many topics that we have discussed simply don't lend themselves to analysis with grouped data. At some point we have to latch on to unit record data. I think the opportunity here is tremendous. There is a great deal of unit record information that is simply sitting at the Department of Statistics, and making unit data records available is a relatively cost effective way of getting that 
Table 1. Review of Labour Market Statistics. Summary of Recommendations

\section{Measuring Change in the Formal Economy}

1. Investigate introduction of individually focused survey of establishments, or enhancement of Labour Cost Index sample, to provide information on occupational earnings, hours worked and contractual conditions.

2. Develop summary measures of labour factor inputs that are compatible with the New Zealand System of Naional Accounts, including industry based estimates of employment measured according to the IIO standard plus a measure based on full-time equivalents and, at some time in the future, a more comprehensive quality controlled measure of labour inputs.

3. Where measures of full-time equivalents are used, make use of within survey measures to establish appropriate ratios for combining full and part-time workers.

\section{The Household Economy}

4. Circulate chapter of report on The Household Economy to interested parties for criticism and comment and, depending on the response, the Labour Market Statistics Unit, in cooperation with the Social Reporting Section and the National Accounts Section of the Department of Statistics, undertake development of a household accounting framework along the suggested lines.

\section{The Dynamics of Changes in Labour Force Participation}

5. Investigate the possible introduction of an ongoing youth cohort survey designed to gather information on labour market and other issues. We see this as ideally picking up a new cohort of 15 year olds (alternatively, 15-19 year olds) each census year and following them at annual intervals for the next fifteen years.

6. Investigate the scope for further development of measures based on the Household Labour Force Survey, including the calculation of transition probabilities for a wider range of variables and the possible introduction of retrospective questions on matters such as recent training activity.

7. Pilot test both annual and pay period income questions for possible inclusion within the Household Labour Force Survey.

8. Further develop the "data laboratory" concept, under which outside users can apply standard and experimental analytic techniques to data bases of the Department of Statistics, and review the procedures used by the Department's Australian and United States counterparts to protect the confidentiality of unit record data released on tape, to see whether they could be adapted to meet New Zealand circumstances.

\section{Education and Training}

9. Support study of the dynamics of transitions such as that from education to working life and the dynamics of movements into education in later life, by increasing attention to longitudinal data bases and improving access to cross sectional data, at unit record level if appropriate (see recommendation 8).

10. Review the range and content of questions currently asked on qualifications and other education matters in the Department's questionnaires.

11. Consider adding training related modules to the Annual Enterprise Survey and the Household Labour Force Survey, as suggested by the Callister review of industry based training.

12. Cooperate with Quest Rapuara in developing indicators on current occupational labour market conditions and trends for inclusion in career leaflets. This information should desirably include up-to-date information on trends in occupational incomes.

13. Keep under review the adequacy of the Department's data bases to support initiatives designed to enhance the range of information available on longer term trends in occupations and skill levels.

\section{Other Matters}

14. Review the range of labour market statistics with a view to increasing the number of parallel tables relating to particular groups in society.

15. Establish the statistical needs of particular groups through consultation with the groups in question, and establish whether it is possible to gather that information in a cost-effective way.

16. The Labour Market Statistics Unit examine the minimum age of working population issue.

17. Estimate and publish an employment ratio series for New Zealand.

Source: Review of Labour Market Statistics 
Figure 1. Links between the proposed developments

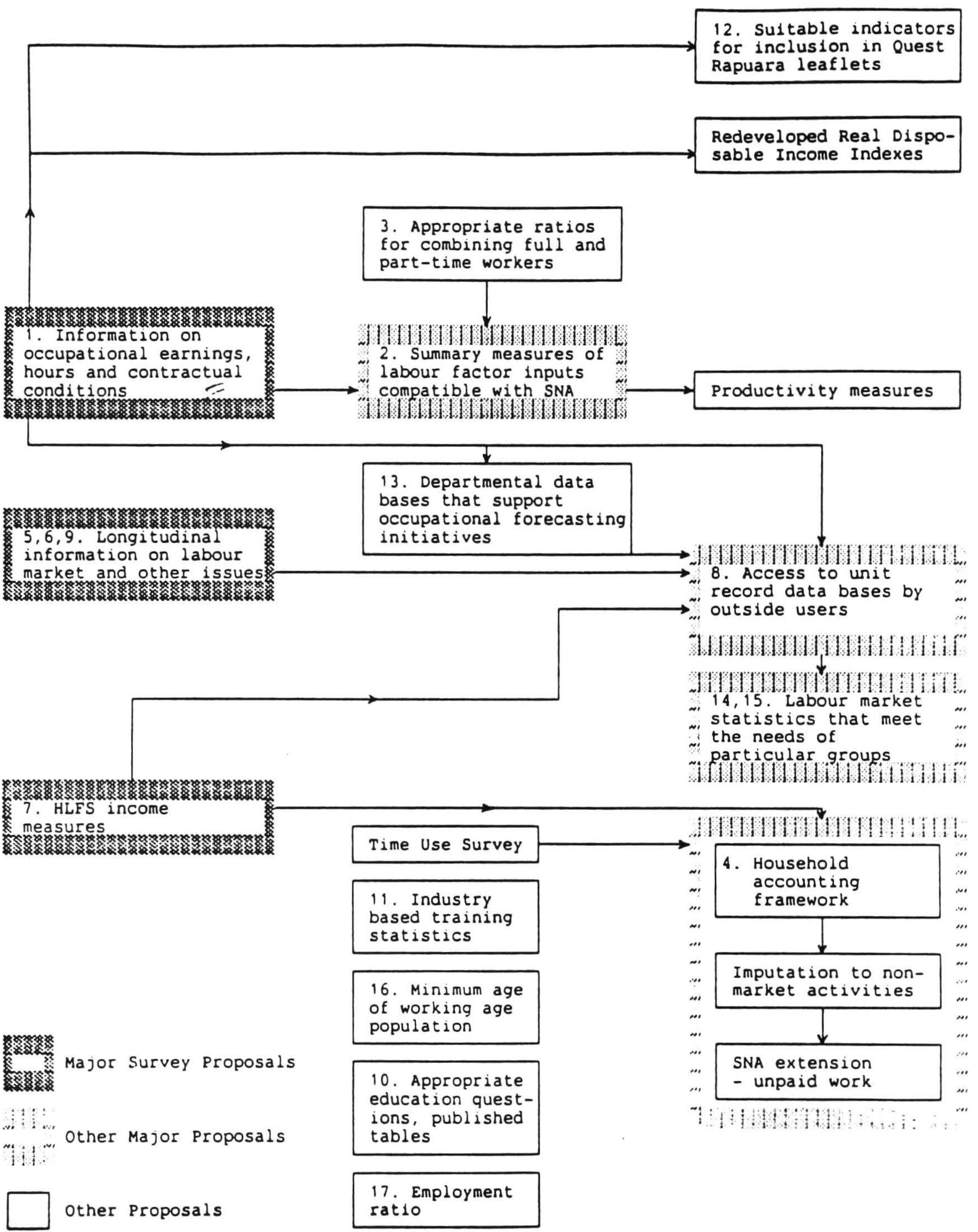

Source: Review of Labour Market Statistics 
information out to researchers. I think a lot can be learned just by allowing access to the current information in unit record form.

I know the 1978 Statistics Act makes it difficult for us to access these data. The laboratory concept has been talked about as has remote access that would allow us to tap into the department's computer and to run programmes that would access the unit record data through their system. Other possibilities would be the release of this unit record data under some restrictions that would clearly not endanger confidentiality. I think a lot more can be done to at least think about these possibilities.

Unit record data is therefore a critical part of the research agenda. For so many of us the idea came up so often during the last two days that people will eventually point to this workshop and talk about the importance of discussing these issues. Dennis has essentially raised the right issues and we simply need to get behind him and the Department of Statistics and really push that these issues so that they are brought to the forefront, discussed and hopefully acted on.

\section{Michael Fletcher, Department of Labour}

From the Department of Labour's perspective we have two main areas of data use: the on-going monitoring advice to the Minister etc. and broader research into the functioning of the labour market in general.

Let me start by recording our appreciation of the Department of Statistics move to establish the Labour Market Statistics Unit. The Unit is obviously going to be extremely busy and its going to need the resources to do the analytical work as well. Its taking on a lot of functions that have been done by other parts of the Department of Statistics including the basic production of labour statistics themselves. Let's hope it will actually have the time to do some analytical work as well.

The first of the two areas that I want to talk about is wages data which has never been very good in New Zealand. It used to be collected by the Department of Labour through the QES and before that the Half Yearly Employment Survey and, of course, through award data which no longer exists. I think in the past we got away with that. It served us well enough but changes in labour market as well as changes in other areas require that we have more detailed data now. Our strong preference is for the more expensive option outlined in the report - that is for the individually based enterprise survey. I don't think that we can get what we need through the labour cost index option. We need something that can link wage data to both the characteristic of the job and the characteristic of the individual, especially basic variables like gender and age. These are relationships that you can't get properly out of the labour cost index .
At present you have an integrated household survey model in which the household economic survey and the Household Labour Force Survey are a base vehicle for supplements and attachments. These involve surveying people at home. I think the idea of using the QES as a way of surveying people at work is also a logical base for supplements and a lot more could be done if it was expanded that way.

As far as contract data goes we wouldn't see the individually based survey as being a replacement for the employment contract survey which we and the Department of Statistics jointly funded earlier in the year. There are two separate needs. Information about individuals and their contracts is useful and I think there should also be data on representation and the content of those contracts rather than just the type of collective individual contract. The other need is for information on the firm and firm labour relations strategies. Does it differ for big firms and little firms? What sort of ownership? What sort of industry and what type of contract arrangements do those firms have? These two types of information are quite separate and we need them both.

The second area that needs developing concerns the dynamics of labour supply, labour participation, and what can be got from the dynamics data coming out of the Household Labour Force Survey. In the Department of Labour we have recently begun to get more of a handle on the dynamics of our own register, and started doing programming work enabling us to look at flows of people on and off the register. There's a lot more work for us to do there, but all of that only relates to a relatively small proportion of the labour market. We need to be able to get more information about the rest of the labour market. I think that is inevitably going to mean more recall questions, and in particular recall questions relating to mobility in general. We also need some more information on occupational and industry changes as well as changes between employment status categories.

There are good reasons for believing there are problems with a lot of dynamics data. Overseas work has shown that in fact many of the transitions are either nonexistent or doubtful. They arise for a number of different reasons and unlike stocks data they don't necessarily cancel out, so there's a problem with that. Our view is that a part of that can be relatively easily dealt with by a re-interview survey, that would cross-check people's answers given at the time of the survey.

\section{Leslie Haines, Ministry of Women's Affairs}

I want to start of by making three general comments and then to move on from there. I'd like to note that I'm here as an individual and the Ministry of Women's Affairs hasn't yet submitted its comments on the report formally, but I expect that what I have got to say and what the Ministry finally comes up with will have quite a lot in common. However they won't be exactly the same. I 
come to the report from three perspectives, from my previous life as a researcher, from my current position as a policy person seeking to use research for policy purposes, and thirdly from an interest in women in policy.

Firstly I would like to emphasise the importance of labour market statistics both on paid and unpaid work across a whole host of policy areas. These will help us to devise employment policy but will also assist our work across a very wide range of areas. Take for example the case of Accident Compensation, where the Ministry were considering what sort of policies there should be on loss of potential earnings. What we really needed to reinforce the kinds of points we wanted to make were decent long range, longitudinal data on what women at any one point in time who are out of the labour market were likely to be doing in ten years or in twenty years time - a situation which also applies to men. If someone is unemployed at the time they have their accident then what can we say about the likely loss of potential earnings for that person over the long term? We don't have that data of course. We therefore try and cobble together Australian data and whatever else is around. There appears to be a real gap across a wide range of policy areas in which labour market statistics are important. I think in general the really big areas that we are lacking information on women are actually all main stream things and you've identified what they are in the report.

I will identify three general areas. First of all, as I said before, the longitudinal data is key and particularly for women because women's labour force participation patterns over their lifetimes are likely to be significantly different at different points of their lives, more so than men, so that's key data for women.

Secondly, from a policy point of view, and this is true for men as well, it is important that we have information on earnings by contract by occupation by industry. The Department of Labour work so far is going to give us very little. There is little on gender in it and that's where we are constantly having to ask questions about what is happening in the labour market; what's the ECA doing for women for example? All we've got is some aggregate statistics on what might be happening with the pay gap in general and what's happening with employment levels and unemployment levels for women. So we would welcome the establishment based individual type of survey in preference to the labour cost index.

The third area where there certainly is a shortage of information is the whole area of unpaid work the discussion in the report about the second area you identify; time use, is one which has a key interest for us right across a lot of different policy areas.

On the collection of longitudinal data through a longitudinal survey, the suggestion in the report is something running for fifteen years, from say fifteen to thirty. From our point of view thirty is not long enough because the labour market changes in women's lives particularly beyond that point are often very great. Such information would be helpful for example in deciding when it is appropriate to work test sole parents and we don't have data like that at the moment.

We welcome the chapter on the household. However I have to say that I personally am a little disappointed that it's all been framed in this sort of speculative box because I think certainly some steps could be taken now. I think we know that we are lacking in some areas and how we could fix that lack of information and we know what we could do with it.

As many of you will know, the Ministry of Women's Affairs has been an advocate for a time use survey for a long time. We have argued that data about what's done with time when people are paid for using it is insufficient. In terms of policy applications understanding the interaction between the paid and the unpaid economy is really essential. Consider for example continuing care for people with disabilities - we don't have any idea of the quantum of people doing that kind of work or how many hours they do it and whether they do paid work as well. So in terms of assessing what policy changes might do to the supply of that kind of labour we are just speculating.

There is a lot of international research being done on time use. Researchers have even used things like how long people sleep as indicators of health and well-being, comparing for example, employed and unemployed people. They have used international data looking at different kinds of tax systems and whether you tax the individual or you tax some sort of household unit and the effect that that has had over a couple of generations on the distribution of paid and unpaid work in the household. In Finland and also in the United States time use data has been used to give better estimates of how much time people spend in their paid work activities as opposed to their unpaid work activities.

We would have liked the report to have made a slightly more positive plug for some kind of measurement of time use and clearly one part of that is to understand labour market activity. The whole work/leisure tradeoff on which a lot of economic theory at least does not really apply to anybody but of course particularly does not apply to women and so is an incomplete base for the formulation not only of policy but across many other policy areas as well.

I would like to make some comments about household transfers and I have to say Dennis, I really liked your table on household transfers although I did have to ask lots of questions about whether it would actually be feasible to get the information. I talked to Robin MacKinlay and Suzi Easting who are both part-time employees at the Ministry and who have a FORST grant to study intra-family income distribution. They are actually interviewing families and finding out about how money is managed in families. One is an anthropologist and the other qualified in social policy 
time. I think between 1966 and 1986 there were four changes to industry and occupation and it is almost impossible to do any proper comparison. Under the computer based systems you can provide two definitions, the new one and the old. So I'm asking for two things consistency between definitions and also over time.

The second issue I should like to raise is a very substantive one behind all these recommendations - the vision of what it means to be in the labour force. I want to argue that the vision underlying our present statistics is becoming increasingly out of date and the database has to be changed to reflect the new reality. That vision, is of the man who starts work at roughly the age of 16 or 18 , finishes work at 60 or 65 who works 40 or 50 weeks per year and 40 hours per week. The essential conception here is of work which is full time. That approach is becoming increasingly irrelevant. I wonder if we should be using as the hour as the unit of analysis much more than full-time equivalent. It could even be hours per week and weeks per year. By increasingly collecting data on this basis we would get away from all the hassles we have had over the years about what is a worker, what is a part-time worker (i.e. 20 hours or 30 hours per week). Once we move away from that vision of a man being a full-time worker all of his life, we can begin to think of a more heterogeneous labour market for men and, of course, for women.

I want to go on for one further step and suggest too that the labour source image is primarily of an employee with the self-employed as a different category. My impression is that we have moved to a situation in which there are many more work source relationships than that of the traditional employee. If I ask how many people here were on some contractual basis with their employer, rather than the traditional employee relationship, the number of hands that would go up would be quite different and more numerous than that which you would have had 10 years ago.

Finally, I think that questions of the dual labour market are becoming increasingly important. Many of the statistics do not handle the dual labour market very well, partly because its a sociological question. But I do wonder whether we should also be thinking about how to obtain more information about the quality of the work place conditions. It is touched in various places I mentioned questions like how much notice has to be given before the worker can be made redundant; whether they have an occupational pension; what control they have over their hours worked (as in glide time operations). A whole range of measures like that may be too much to ask those at the moment but that seems to me to be one of the crucial issues in understanding the employment contract. Indeed one of the benefits of the new employment contract that is the increased codification of working conditions. Perhaps we statistically should be trying to track that.

\section{Paul Brown, Department of Statistics}

I'd like to make a couple of comments on what you said Brian. The point you made, on integration and standardisation is very well made. It is a very important point and its one that has bothered us for some time. The restructuring in the department, in setting up a functional organisation and having a group whose prime focus is analysis is hopefully going to let us address that problem. The best people to standardise are the people who analyse and use the data. They are the ones who experience the frustrations of dealing with porrly standarised data..

Dennis Trewin is the new General Manager of the National and Regional Statistics Group in the department. Dennis' job is to bring together all the subject matter areas in the department, national accounts, labour market, social policy, government accounts, etc and the thing that will interest many of you here is the interconnections between those areas. We've just talked about labour market today. But its very important in terms of standardising generally - there are connections between national accounts and labour market statistics, and social policy concerns in labour market. There are a large number of connections you can make. That was my first point.

On the fulltime part-time distinction, I wonder to what extent that's now an anachronism. The fulltime and parttime dichotomy comes from having a measure of labour based on instruments which did not allow us to collect hours workedand where the next best thing was to try define part-time and fulltime. Once you start collecting hours of work I think you've got a much better measure of labour input and that's what you should use.

\section{Dennis Rose, BERL}

I'd like to comment briefly on two additional things. I do not dispute the utility of an hours based measure and in our section on the household economy you will find one of the input measures is in fact hours. The other point is that the classification at the back of the report was intended to be accompanied by a statement of ideal content under each of those categories. I've tried to just write a brief few paragraphs under each of those headings saying what ideally would we want there, its not an exhaustive listing and anything that's important can be tagged on.

\section{Fraser Jackson, Victoria University of Wellington}

The whole of this set of proposals is very interesting and, as we would expect from Dennis, its got some very rich possibilities. I say that to begin with because I want to make some remarks which I think are quite critical of one aspect of the proposals. They seem to me to be focussing on yesterday's problem. If we look at these comments in terms of the economists traditional way of thinking about markets - both the demand and the supply side of the market - nearly all of the information seems to be very largely concerned with what is happening on one 
research and when I started trying to talk about transfers it didn't make any sense either to them or reflect the behaviour of the people who they were interviewing. They said the idea of transfers does not describe what occurs in families. They talked about how in a large number of cases until relationshipsactually fall apart, both people own everything and everything is for the common good. Nobody owns half, so the idea of trying to divide expenditures by who benefits is a very foreign concept for a lot of households. They would prefer it to be seen in terms of access and control of money in households. What they are trying to do in their work is to develop some proxies and the best one they have come up with so far, is how couples organise their bank accounts, whether they have two joint accounts, two separate accounts or pool it. They think that may be found to be a good indicator as to who has access in the house to finance and who actually has the control. However, their analysis will develop these concepts further.

I would certainly agree with you that extensive imputation of values and development of satellite accounts is certainly premature at this stage. We could see a great deal of use for time use data and I know a lot of other government policy agencies who would actually use time use data a lot as well. Lets keep on talking about how we might try and measure household transfers and watch what other people are doing and see what their research says as well.

The only other thing I would like to add to that is that when I was a researcher I got frustrated because we never had any measures of how much work was temporary and how much work was permanent. There would be definitional problems but I know in some other countries they do. Given that we expect that there is a lot more short duration work around now than there used to be, we probably now should be making some kind of attempt to measure it.

\section{Discussion from the Floor}

\section{Paul Brown, Department of Statistics}

Can I just start it rolling by invoking the chairperson's prerogative to make the first comment. What I would like to hear a little bit about is not just what data you need but some of the uses of it. We have a tendency, and I think we have done this today, to talk a lot about the wonderful collections we could put in place. Aalthough Leslie, you have done very well, you have focussed on your specific needs. To be provocative, how important is measuring dynamics? This is a very complex and expensive area for a Statistics Department and one would therefore want to know the range of uses. What's come up now that wasn't there before, that says we should be measuring more dynamics? That is just a starting comment, and now I'd like to open it up to the floor.
Phil Briggs, NZ Institute for Economic Research (NZIER)

Could I ask a question about the employment contract surveys following up on something that Michael said. Is this going be a permanent survey?

\section{Michael Fletcher, Department of Labour}

It is yet to be decided whether it will be continued or not. That is an issue to be talked about between us and the Department of Statistics. Personally I think there is a strong need for it to continue.

\section{Phil Briggs, NZIER}

If it isn't continued it might put the emphasis on collecting more information on contracts through other mechanisms, such as the Department of Labour's collection of contracts covering 20 or more employees. I see two aspects to the need for information on contracts. One is linked to the firm, the way the firms choose to or end up organising certain types of contracting arrangements. The other concerns individuals and the impact on them and differences between individuals.

\section{Paul Brown, Department of Statistics}

Phil what is still being thought about is what are we going to do with it. Part of what Michael is saying is that there are different ways of skinning a cat and we are still getting an idea of what the range of uses are. Even though its been with us a little time now, I think we need to clarify its purpose and this is a something the research community might like to consider. What is your research agenda, what are the sort of questions you want to ask? Once you establish a survey it is likely to be there for a while. It's an investment and we need to be sure it will be usedwell, not just now, but in the future.

Government has great expectations for the community to provide, and that includes local bodies and all sorts of different community social services readily understandable. For them to provide they need to have ready access to information to make decisions that often have to be done very quickly.

\section{Brian Easton}

I'd like to make a few suggestions. The first is that there is a section in the report which talks about the need for consistency between the different databases. There is a particular problem here because this is not just databases within the labour force unit itself but its between a whole range of other databases. I'm thinking particularly of the national accounts. It is a pity it is not in one of the specific recommendations because it is so important. In addition it is important that when the databases are developed that there be a consistency over time as well. The Statistics Department have on occasions ruined their databases by changing definitions so that you can't actually work through 
side of that market - the labour supply side of that market and the characteristics of the people that are available in that market.

If I look through the set of recommendations in the report, the household economy part is largely concerned with that, the dynamics of labour force participation is concerned with it, the education and training is very largely concerned with it and as are most of the other matters. That leaves us with three items at the beginning that potentially focus on the demand side and yet if I think about the problems in New Zealand it seems to me that what we've had is a labour supply which has been continually growing through dynamics of its own and a later demand which has not. We need to try and develop a better balance in the set of things that we are trying to measure in this market I don't want to pretend that its easy, I just want to stress the fact and urge that it be given a lot more attention. Certainly if you do try and do some things where you are wanting to look at the demand side, very frequently there are real difficulties and enormous gaps and you find you're extremely constrained.

One of the things that I think is extremely important links to the issues that Brian Easton raised. We should try and make sure that the items that are in this report can potentially link to information sources in the register of enterprises and in the other databases that are available in the department so that hopefully people who are endeavouring todo some analysis of the interaction between changes in the situation that enterprises face can hopefully trace through some of those effects into participation measures. I will not try and elaborate that any further but I do think its an important thing for us to consider.

The second comment that I would like to make, and its one that covers a large part of this area but particularly relates to education in training. It is the importance of providing enough information in the datasets so that when we come to analyse it we can deal with the well known sample selectivity problem. Very commonly, in the education literature, you end up with the sort of comment that we will take all the people that have had this education and all the group of people who have not had this education and we'll make a comparison between them. Now there are a lot of factors that will influence the decision for them to goon to further education and in making the comparisons those factors are nearly always ignored. Generally you find a few comments about potential biases and that's all that's said and all that can be done. In many circumstances there are pieces of information which would enable consideration of some of those issues. In particular there will be cases where it is possible to consider groups of people who have similar backgrounds who did and did not or were or were not exposed to the additional education. I would urge that in thinking about these databases we go beyond some of the traditional variables we've had and try explore some of these additional issues.

\section{Dennis Rose, BERL}

Demand side considerations are certainly important and it was in our minds that an individually focussed questionnaire administered through an establishment base would create the potential to link up data on the establishment databases to the individuality focused survey but that takes us back to the question of whether the researcher can access unit record data.

\section{Fraser Jackson, Victoria University of Wellington}

There is some work in the United States, where people are actively exploring the conditions under which enterprises might look at changes in their employment or the number of hours at work and there doesn't seem to be any reference to this in here. It may come somewhere else in the Department of Statistics categories but if we are talking about the labour market its really central to all of the participation issues because you can't interpret them unless you've got some information about the demand side as well.

\section{Prue Hyman, Victoria University of Wellington}

First a reaction to that - I think what you end up with is often neither supply nor demand, but a hybrid, when examining participation rates. I agree with almost everything Fraser and Brian said in response to the remarks of the commentators. One does rather sigh on unit record and longitudinal data - we've been saying the same thing for twenty years and little has changed. So I hope it gets somewhere this time. In terms of the research questions and Paul and Leslie's points, superannuation is another important area for longitudinal data. With the desire by government for people to save more to meet their own needs in old age, so that national superannuation could become just a safety net, one needs such data to see how possible it is for different groups to save and accumulate enough claims on resources. Women still have less ability to save for old age with lower average earnings and less years in the full time labour force due to home commitments. To make sensible decisions in that area, we also need proper earnings data by gender and occupation/industry, not just income data in broad bands from the census. That earnings data is also needed for many other questions about what is going on in the labour market, including the extent of discrimination.

The other thing I wanted to make a comment on, and the only place in which I was surprised by Leslie's comments is on the household economy. I welcome a full scale time use survey if we can get it - the use of time is a crucial economic and social variable. Feminists have talked for a long time about the value of unpaid work and about counting it in GDP. Satellite accounts can be seen as a second best option. Economists have begun to listen and point out the misleading nature of current figures, since on the whole unpaid activity is probably countercyclical. Hence GDP as currently measured exaggerates both for 
the total economy and for some households the impact of recession and boom. However, as economists jump on the bandwagon, I have increasing doubts about adding unpaid work to GDP. I still want time use measurement, but money values are another matter. My doubts come from questioning whether the third party criterion, the usual one used (could you pay a third party for the service in the market place?) is useful. Where do the boundaries lie and, more fundamentally, does one want simply to add on unpaid activity? This simply accepts the conventional view of what is valuable - only that which can have an imputed money value and what is value - price.

A final comment on one part of Dennis's report that I don't think I understood - the intra household transfer table. What are the methodology and sources for estimating those transfers? I am not concerned at all about the table being intrusive. It seems to me to be much more of concem that we don't worry about whether or not there is any reasonable access for other members of the household apart from the people directly obtaining the cash. But I don't know whether you are talking about simply making assumptions to estimate the transfers - i.e. assuming that every adult in the household has access to the same resources, and therefore estimating the transfers as a residual. That would be hopeless, but if not, how do we go about it? Relating it back to Robin and Suzi's work, I was a bit surprised by Leslie's comment that they were coming up mostly with households where both adults felt they jointly owned everything for the common good. Earlier overseas studies have found that you can get something meaningful out of the concept of separate command over resources. In looking at transfers and how much discretionary spending people have for their own purposes, some have come up with many women having less than their spouses. When the marriage is harmonious that may or may not matter much. But social policy decisions on the family frequently assume harmony and equal sharing, and many families are still based on the traditional division of labour in paid and unpaid work. If the marriage doesn't work out these issues matter a lot and have implications for matrimonial property law, child support, women's position relative to men's after divorce and so on. So I'd like Dennis to say a bit more about his transfer table.

\section{Dennis Rose, BERL}

Could I briefly respond? The basic framework that I had in my mind is as follows. Let's say at this moment we are talking in terms of an annual income for a person. On table 3 of the Review we had the annual income for a full-time male in paid employment and we separate that out as their labour income, other income and expenditure and transfer payments in aggregate. I see those transfers as cash payments to other people. I had cash flows in mind and then the fourth table is saying to whom that cash is transferred.

\section{Prue Hyman, Victoria University of Wellington}

Dennis why didn't you work on the expenditure side rather than the income side?

\section{Dennis Rose, BERL}

There is also the question of who benefits from the expenditure. The mother buys food for the children. Do we record that as expenditure against the mother or against the children? Expenditure may offer a better way of tackling the transfer issue but can I just add one thing; I found their suggestion that most of the households Robina and Suzi are interviewing have no concept of personal money and no concept of themselves as individuals in the household fascinating.

Someone asked about individually focussed questions within an enterprise based survey. We have not thought of doing that. We talked about it a number of times and it did seem a problem to ask respondents about the ethnicity of other persons not so much in the Maori non-Maori area as, in dealing with new minority groups. We did consider the issue and judged it was not an appropriate question.

\section{Roger Hurnard, Treasury}

\section{[Abbreviated transcript]}

Is there any attempt to try and get an explicit link to individuals on the household survey through their employers or is there just to many [] problems? [Discussion of ways to establish the link could not be transcribed, Ed.].

\section{Paul Brown, Department of Statistics}

There are many design options. Your design option is chosen on the basis of the uses you wish to make of the data. Your points are quite right and in designing longitudinal surveys one can adopt a number of approaches They generally involve panels which ensure that you maintain get the right coverage. But in the end it comes down to what are the key things you are going to be measuring and that determines what combination of methods you should be using.

\section{Brian Easton}

There are two longitudinal studies in New Zealand. Both have been going for about 20 years of newly born children in the mid 1970s and are now coming up to teenage years. Although the prime focus of the studies has been medical, in each case it might be appropriate to encourage funding to pick up economic data of these people because it is expected that these people will be followed indefinitely into the future and also their children and the grandchildren. Already at least the Otago study has already done some work on labour issues so this may be the el-cheapo way of getting your requirements. It may well be that the Statistics Department could think about that sort of strategy in the 
interim in this case probably two generations. David Fergusson's Christchurch Child Development Study is based at the Christchurch Medical School, and Phil da Silva's Dunedin Multidisciplinary health and Development Study is based at the Otago University Medical School.

\section{Philip Briggs, NZIER}

I'd like to go back to the issue of labour demand which has been touched on before. The major source of information on labour demand is the quarterly employment survey and as Michael Fletcher said there has always been problems with the QES and I think there still are problems. Accuracy is what we are interested in here and of course one of the problems with the quarterly employment survey is that it doesn't survey firms which have less than two full-time employees. Now I understand why it doesn't do that. Its actually very difficult to survey small companies; in fact the NZIER doesn't survey small companies in its own quarterly survey of business opinion. Having said that though, it would be helpful to have more accurate data on what's happening in terms of labour demand in small businesses and I' $m$ hoping that these new approaches such as the English New Earnings Survey approach, will be useful. This type of survey is actually a person-based survey so it should pick up wages data on those employed in small businesses. I'm not sure that the Australian approach would do this; does it actually cover small business?

\section{Paul Brown, Department of Statistics}

We do in fact Phil. The QES hits the large group in the full survey which is in February. Although, as Michael points out, we don't cover the whole field, so its the other quarters where we get into that smaller sample.

\section{Michael Fletcher, Department of Labour}

But you are also not actually giving them the full questionnaire are you? I think its a really important point. Its just a matter of history and in the old days that was much less important - now its much more significant.

\section{Phil Morrison, Victoria University of Wellington}

I'd like to make a couple of comments. I'm still concerned that we haven't responded to Paul's question at the beginning of the session which is "What are the key questions we are going to ask?' I have a feeling that in the absence of doing so, it's not the research questions that are going to determine what is collected but that the data that is collected is going to determine the research questions. If this is the case then we are essentially handing over to data collection agencies the issue of setting our research agenda. So I think that makes it even more imperative that we spend more time thinking about what really are the key research questions. This information can be fed back to Dennis and the others to help them tailor data collection.
I'd like to make a couple of additional small points which arise from the previous discussions. Its quite clear that, as someone else mentioned, we are in a period of rapid change and one of the areas that's under considerable transition is occupation. Its very important that we start taking a much broader view of what occupation actually is. We need to rethink the way we ask people what they (think they) do and to take a broader, well rounded, look at what they actually do. It may no longer be satisfactory (if it ever was) to simply ask people their occupation. We need to ask those other questions necessary to build up a proper measure of what a person actually does in a particular organisation or at home or wherever they happen to work. Only then can we begin to understand the subtle ways in which the nature of teaching, joinery or drain laying has changed over the years.

The other point I would like to make concerns this whole question of 'hours of work' - an issue raised by Leslie who noted the growth of temporary work and the need to monitor it, and by Brian who highlighted the importance of the hour as a basic unit of analysis. Our most comprehensive picture of the duration of peoples paid work comes from the quinquennial census of population. The census question on hours of work however remains inadequate because it can be answered in many different ways by people each of whom think they are answering the question correctly. In the 1991 census we were asked how many hours you worked last week and many of us can't actually remember so we just say $\mathbf{4 0}$ whereas it may have actually been 35 or 55 or 65 . If we are going to have an 'hours of work' question it must be very explicit so that respondents know exactly what is being measured. At present, there is a high degree of measurement error and I suspect it is correlated with age and other attributes as well as the type of work people actually do. 4

\section{Roberta Hill (NZISR)}

I'd like to pick up on Philip's point about occupations and how we need to have a better understanding of what we mean by a particular occupation. I cover things from a very different perspective, very much from a field work perspective and from an interest in technological change and in workplace reform issues. As you were talking I was thinking about the occupations that I focussed on in the early 1980's when doing a major study on the newspaper industry which was undergoing major technological change. The occupation of printer-linotype operator and compositor was being fundamentally transformed by the introduction of technologies of electronic phototypesetting. Alongside that occupation were clerical workers who were similarly undergoing major transformations in their occupation. What happened as I focussed very closely on the occupation - indeed underwent training as one of the workers being retrained - I had a very close look at the detail of the respective occupations and what emerged was how very similar the work was, but that was denied by each of those categories of workers or at least by certainly the male printing trades people. What also emerged was the extent 
to which the clerical workers recording phone ads were doing work that was simply unrecognised because it was never seen as part of that occupation. They were doing a range of printing and customer relationship tasks that were simply not recognised in the taken-for-granted assumptions about clerical work vis a vis printing trade occupations. So what I am certainly wanting to pick up on is the extent to which "work" and "occupations" are socially constructed and the extent to which technological changes have virtually transformed a number of occupations in this country; and moreover with the push for workplace reform in industry, which is changing the way production and service work are organised and managed, occupations are now much more fluid. There is a sense in which we can't really talk about something enduring over a particularly long period of time, and that has implications for any attempt to try and compare occupations over time.

\section{Paul Brown, Department of Statistics}

Yes it poses a major problem for the statistician who presents to you a classification. Brian's made the point, you want to know what occupational changes occurred over a period of twenty, thirty years. There is an assumption in there we are talking about the same tasks, the same things.

\section{Jane Higgens, Christchurch}

\section{[Abbreviated transcript]}

I agree with you [ ] I've been doing a study of the Christchurch Youth Labour Market using occupations from census data and have noted the number of people who have increased in the occupations not elsewhere classified. [Discussion on way occupational classification does not match respondents own or employers understanding of their occupation - Ed.]. In my interview [] with employers and workers and so forth I showed them the standard classification modification and said, "this is the group I'm looking at", and they say, "Oh no that's not right, plumbers don't fit in there and welders don't fit in there"; so I think maybe something needs to be looked at in that classification.

\section{Brian Easton}

I would like to take up Paul's query of what questions are researchers likely to ask of the data. Research is driven in two ways. One is on supply side; if you produce interesting data researchers will look at it. If new technology comes in like high powered computers and individual unit records, researchers will use them. Supply side responses are not much help in determining what data should be produced. But the other way is demand driven, although of course the two interact. This research is primarily a response to the issues of the day (or perhaps the issues of the previous decade.) To think about it, cut the researcher out altogether, and think about what are going to be the issues of the next decade and from that infer back into what will be the databases required. Actual researchers don't have a lot more competence in that area than anyone else. The approach is explicit in Dennis' report when he was thinking about educational training issues; women in the future of the economy; and the question of unemployed because it doesn't look as though it's going to go away. So rather than ask the researchers what is it that they need, let us try to assess what are the issues going to be in the next ten years, and so what are the databases that tackle them, leaving the researchers to respond to these external pressures.

\section{Paul Brown, Department of Statistics}

Well, I would like to draw our discussion to a close now. Its been very valuable hearing what you've said and we've covered quite a range of things. Issues have been raised I think that I certainly hadn't thought of, and I know my colleagues in the Department Statistics would agree that there are some extremely important things that we have picked up. The session has been recorded and with it down in writing you can hold us accountable for acting on the issues you have identified. In eighteen months or so I hope we can meet here again to assess progress. So, on that note, I'd like you to join me in thanking the discussants for their comments and thanking Dennis for his presentation.

\section{Notes}

${ }^{1}$ A copy of the full review document is available on request from the newly created Labour Statistics Unit, Department of Statistics, Wellington.

2. The assistance of the Department of Statistics in making the initial transcription from tape is gratefully acknowledged. The willingness of participants to subsequently edit their oral comments was appreciated. While I have made every effort to identify those who offered comments at the workshop there were one or two instances where this was not possible. May I apologise to those those brief comments may not have ended up here and emphasize that this was purely a reflection of variation in tape quality. Final corrections to the transcript were made by Carol Salmon, Secretary, Department of Geography whose assistance here and throughout the conference is gratefully acknowledged.

3 There are a lot of people in universities and research institutions and so on that I would have liked to have spoken to, so we put a recommendation in the report that the first thing that should be done with it was to circulate it more widely for criticism and comment. I should mention the failure, to acknowledge in our report the existence of Raymond Harbridge's database on employment contracts. It was an oversight by me. I'm well aware of that base which should have been just mentioned at the appropriate place in the report.

4. When I made this remark at the workshop I was drawing on my own experience in analysing the responses from this census question. It has since come to my attention 
that the US Bureau of the Census is beginning to address exactly this problem. Using interviewer focus groups to help design questions they found that "when respondents were probed extenstively about their actual work patterns, it was found that the [hours of work] question did not fully capture the hours of those who worked in more than one job or the variations from week to week in the hours of those who worked part time. Only after a series of questions has forced the respondent to make a mental review of the actual work that he or she has done over the past seven days is the question asked: "How many actual hours did you work last week?" Note incidentally that the word 'actual' does not appear in the personal schedule of NZ census questionnaire. See B.E. Bryant 1992 How surveys are changing at the US Bureau of the Census (Asian and Pacific Population Forum 6 (3) : 72.[Ed.] 